\title{
Nuclear Performance Calculations for the ELMO Bumpy Torus Reactor (EBTR) Reference Design
}
R. T. Santoro
J. M. Barnes 


\section{DISCLAIMER}

This report was prepared as an account of work sponsored by an agency of the United States Government. Neither the United States Government nor any agency Thereof, nor any of their employees, makes any warranty, express or implied, or assumes any legal liability or responsibility for the accuracy, completeness, or usefulness of any information, apparatus, product, or process disclosed, or represents that its use would not infringe privately owned rights. Reference herein to any specific commercial product, process, or service by trade name, trademark, manufacturer, or otherwise does not necessarily constitute or imply its endorsement, recommendation, or favoring by the United States Government or any agency thereof. The views and opinions of authors expressed herein do not necessarily state or reflect those of the United States Government or any agency thereof. 


\section{DISCLAIMER}

Portions of this document may be illegible in electronic image products. Images are produced from the best available original document. 
Printed in the United States of America. Available from National Technical Information Service

U.S. Department of Commerce

5285 Port Royal Road, Springfield, Virginia 22161

Price: Printed Copy $\$ 4.50$; Microfiche $\$ 3.00$

This report was prepared as an account of work sponsored by an agency of the United States Government. Neither the United States Government nor any agency thereof, nor any of their employees, contractors, subcontractors, or their employees, makes any warranty, express or implied, nor assumes any legal liability or responsibility for any third party's use or the results of such use of any information, apparatus, product or process disclosed in this report, nor represents that its use by such third party would not infringe privately owned rights. 
Contract No. W-7405-eng-26

Neutron Physics Division

\title{
NUCLEAR PERFORMANCE CALCULATIONS FOR THE ELMO BUMPY
} $\underline{\underline{T}}$ ORUS REACTOR (EBTR) REFERENCE DESIGN

\author{
R. T. Santoro \\ J. M. Barnes ${ }^{\dagger}$
}

Date Published - December 1977

\section{${ }^{\dagger}$ Computer Sciences Division.}

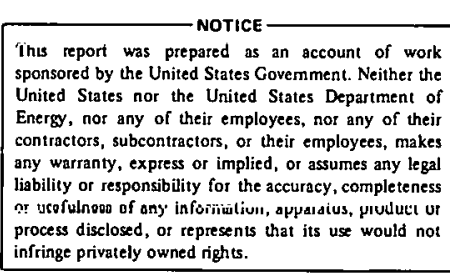

This report was prepared as an account of work United States nor the United States Depertment of Energy, nor any of their employees, nor any of their any warran, subcontractors, or their employees, makes liability or responsibility for the accuracy, completeness

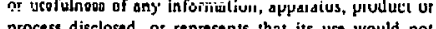
infringe privately owned rights.

NOTICE Thls document contaıris intormation of a preliminary nature. It is subject to revision or correction and therefore does not represent a final report.

OAK RIDGE NATIONAL LABORATORY

Oak Ridge, Tennessee 37830 operated by

UNION CARBIDE CORPORATION

for the

DEPARTMENT OF ENERGY 


\section{THIS PAGE}

\section{WAS INTENTIONALLY \\ LEFT BLANK}




\section{Abstract}

The nuclear performance of the ELMO Bumpy Torus Reactor reference design has been calculated using the one-dimensional discrete ordinates code ANISN and the latest available ENDF/B-IV transport cross-section data and nuclear response functions. The calculated results include estimates of the spatial and integral heating rate with emphasis on the recovery of fusion neutron energy in the blanket assembly and minimization of the energy deposition rates in the cryogenic magnet coil assemblies. The tritium breeding ratio in the natural lithium-laden blanket was calculated to be 1.29 tritium nuclei per incident neutron. The radiation damage in the reactor structural material and in the magnet assembly is also given. 


\section{Introduction}

This report summarizes the results of nuclear performance calculations that were carried out in support of the design of the ELMO Bumpy Torus Reactor (EBTR) being undertaken at the Oak Ridge National Laboratory. This work was performed as part of a multi-disciplined effort involving plasma, magnetic, design, and nuclear engineering input to examine the potential of the EBTR as an alternative to the Tokamak confinement concept as a source of fusion derived energy. In an earlier study several reactor configurations and compositions were compared. The work reported here, as well as in companion reports,, 3 is a continuation of that study, but with emphasis on a specific design concept.

Neutronics calculations were performed to assess the capability of a lithium-laden blanket assembly for recovering the kinetic energy of the fusion neutrons and secondary gamma rays in the form of heat and for breeding tritium. The capability of the shield assembly that surrounds the blanket for protecting the magnet coil assemblies from the radiation leaking through the blanket was also evaluated by comparing the energy

- deposition rates in the coils as a function of shield composition.

All of the calculations were performed using one-dimensional radiation transport methods. While it is recognized that multi-dimensional neutronics analyses may reveal more detailed information, particularly with respect. to penetrations and other anomalies in the blanket-shield assembly, these were not performed because of the frequency of design changes.

The descriptions of the blanket-shield assembly considered in this s.tudy and the calculational procedures and nuclear response data used to estimate the performance of the EBTR are discussed in Section II. The 
results of the calculations are presented and discussed in Section III.

II. Details of the Reactor Model and Methods of Calculation

The dimensions of the blanket, shield, and magnet assemblies in the EBTR are summarized in Table 1. Also given in the table are other design parameters. The reactor has a major radius of $60 \mathrm{~m}$ and a minor radius of $1 \mathrm{~m}$. The plasma region is surrounded by a $0.60-\mathrm{m}$ thick blanket assembly that is isolated from the plasma edge by a $0.20-\mathrm{m}$ thick "cold zone". The blanket has the functions of (1) recovering the energy of the fusion neutrons and secondary gamma rays in the form of heat, (2) breeding tritium, and (3) acting in combination with the shield to reduce the intensity of the radiation incident on the cryogenic magnet coil assemblies. Surrounding the blanket assembly is a $0.55-\mathrm{m}$ thick shield. The shield is separated from the blanket by a $0.30-\mathrm{m}$ thick maintenance void. The shield attenuates the nuclear radiation leaking from the blanket and serves as a thermal barrier between the high temperature blanket and the cryogenic magnet coils. The magnet coil assembly is $0.85 \mathrm{~m}$ thick and is isolated from the outer edge of the shield by a $0.5-\mathrm{m}$ thick gap.

The dimensions and materials used in the blanket assembly are summarized in Table 2. The configuration and thicknesses of the components given in the table correspond to those used in the one-dimensional representation of the blanket in the radiation transport code and are taken from detailed engineering drawings cited in Ref. 2. The blanket assembly is constructed of three materials: stainless steel-316 as the structural material, natural lithium as the fertile material, and helium at high pressure (70 atmospheres) as the coolant. The rationale for selecting 
Table 1. EBTR Reference Design Paramters

Major radius (m)

Minor radius $(\mathrm{m})$

Plasma radius $(\mathrm{m})$

Cold zone (m)

Blanket thickness (m)

Maintenance void $(m)$.

Shield thickness (m)

Magnet separation (m)

Magnet assembly thickness (m)

Total thickness (m)

Plasma volume $\left(\mathrm{m}^{3}\right)$

Plasma surface area $\left(\mathrm{m}^{2}\right)$

Plasma toroidal length $(\mathrm{m})$

Neutron wall loading $\left(\mathrm{MW} / \mathrm{m}^{2}\right)$

Neutron flux $\left(\mathrm{n} / \mathrm{cm}^{2} / \mathrm{sec}\right)$
60

1

1.00

0.20

0.60

0.30

0.55

0.05

0.85

3.55

$1.18 \times 10^{3}$

$2.84 \times 10^{3}$

$3.77 \times 10^{2}$

1.47

$6.52 \times 10^{13}$

these materials is given in detail in Ref. 2 and is based, to a large extent, on experience gained from previous fusion reactor blanket studies carried out at $\mathrm{ORNL}^{4}, 5$ and elsewhere ${ }^{6}$ wherein a variety of blanket configurations and compositions were considered.

Briefly stated, however, stainless steel was chosen for the blanket structure because of its availability and since no special technology must be developed for alloying or fabricating the material. Also, stainless steel is compatible with lithium over the temperature range $\left(\sim 500^{\circ} \mathrm{C}\right)$ at which the blanket operates. A particular concern in the use of stainless steel, however, is the lifetime of the wall facing the plasma. Radiation damage to the stainless steel components in the vicinity of the plasma from the fusion neutrons and non-penetrating particles may 
Table 2. EBTR Blanket Assembly Materials and Dimensions

\begin{tabular}{rlllll}
\hline Zone & Material & $\begin{array}{c}\text { Outer } \\
\text { Radius } \\
(\mathrm{m})\end{array}$ & Zone & Material & $\begin{array}{c}\text { Outer } \\
\text { Radius } \\
(\mathrm{m})\end{array}$ \\
\hline 1 & Plasma & 1.000 & 20 & SS-316 & 1.4133 \\
2 & Cold zone & 1.200 & 21 & Lithium & 1.4137 \\
3 & SS-316 & 1.2008 & 22 & SS-316 & 1.4122 \\
4 & SS-316 & 1.2014 & 23 & Helium & 1.4258 \\
5 & Lithium & 1.2019 & 24 & SS-316 & 1.4263 \\
6 & SS-316 & 1.2025 & 25 & Lithium & 1.4267 \\
7 & Helium & 1.2176 & 26 & SS-316 & 1.4272 \\
8 & SS-316 & 1.2182 & 27 & Lithium & 1.5185 \\
9 & Lithium & 1.2187 & 28 & SS-316 & 1.5193 \\
10 & SS-316 & 1.2193 & 29 & Lithium & 1.5197 \\
11 & Lithium & 1.3068 & 30 & SS-316 & 1.5202 \\
12 & SS-316 & 1.3074 & 31 & Helium & 1.5318 \\
13 & Lithium & 1.3079 & 32 & SS-316 & 1.5323 \\
14 & SS-316 & 1.3085 & 33 & Lithium & 1.5327 \\
15 & Helium & 1.3236 & 34 & SS-316 & 1.5332 \\
16 & SS-316 & 1.3242 & 35 & Lithium & 1.5508 \\
17 & Lithium & 1.3247 & 36 & SS-316 & 1.5603 \\
18 & SS-316 & 1.3253 & 37 & SS-316+Li & 1.7810 \\
19 & Lithium & 1.4128 & 38 & SS-316 & 1.8000 \\
& & & & & \\
\hline
\end{tabular}

${ }^{\mathrm{a}} \mathrm{SS}-316-63.6 \% \mathrm{Fe}, 18 \% \mathrm{Cr}, 13 \% \mathrm{Ni}, 2.6 \% \mathrm{Mo}, 1.9 \% \mathrm{Mn}, 0.9 \% \mathrm{Si}, \mathrm{Ti}, \mathrm{C}$.

$b_{\text {Natural }} 1$ ithium $=7.42 \% 6 \mathrm{Li}+92.58 \%{ }^{7} \mathrm{Li}$.

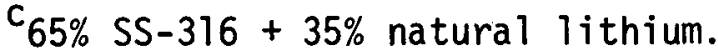

${ }^{d}$ Referred to as the blanket gamma-ray shield. 
necessitate replacement of these components during operating lifetime of the reactor. Natural lithium was chosen as the tritium breeding materials because tritium recovery and heat removal problems were considered to be less severe in natural lithium than in other lithium compounds. Helium was selected for the blanket coolant over other materials, including molten salts and lithium, despite the problems associated with the high pressure containment of the gas.

The dimensions and composition of the shield and magnet assemblies are given in Table 3 . Several shield compositions were considered and a

Table 3. Dimensions and Compositions of the Shield and Magnet Coils

Thickness

(m)

Shield Assembly

Structure

SS-316

0.0381

Bulk shielding material

$\mathrm{SS}-316+\mathrm{H}_{2} \mathrm{O} \cdot \mathrm{B}^{\mathrm{a}}$

0.4738

Structure

SS-316

0.0381

Shield-Magnet Separation

0.05

Magnet Coil Assembly

Bobbin

$\mathrm{SS}-316$
$\mathrm{Cu}+\mathrm{NbTi} \mathrm{b}, \mathrm{c}$

0.05

Coil

SS-316

0.70

Structure

SS-316

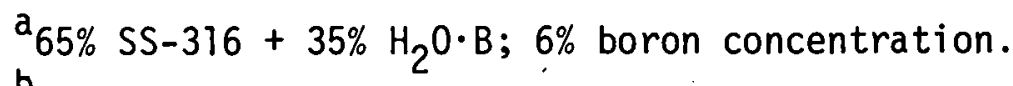

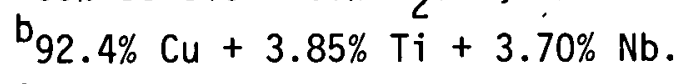

${ }^{\mathrm{C}}$ These materials are homogenized for the radiation transport process. 
discussion of the effectiveness of the various shield compositions versus nuclear heating in the magnet coil is given in Section III. The magnet conductors were taken to be $\mathrm{NB}-\mathrm{Ti}$ in a copper matrix.

A1l of the neutronics calculations were carried out using the onedimensional discrete ordinates code ANISN 7, a $P_{3}$ scattering expansion, and an $\mathrm{S}_{12}$ angular quadrature. The transport cross sections were taken from the DLC-37 8 library and collapsed to a 35-neutron arid 21-gamma-ray' єnergy group subset. The energy deposition rates in the blanket, shield, and magnet coils were estimated using neutron kerma factors obtained from MACK 9 and MACKLIB ${ }^{10}$ and photon kerma factors generated by SMUG ${ }^{11}$. Radiation damage response functions were obtained from the data base RECOIL . 12

\section{Discussion of Results}

The spatial distribution of the nuclear heating rate in the EBTR reference design is shown in Fig. 1. The upper curves show: the energy deposition rate from neutrons and secondary gamma rays and the lower curves show the energy deposition rate from neutrons only. The data are normalized to a neutron-wall loading of $1.47 \mathrm{MW} / \mathrm{m}^{2}$. The peak heating rate in the blanket assembly is $13.5 \mathrm{w} / \mathrm{cm}^{3}$ and occurs in the stainlesssteel surface facing the plasma region. In the inner portion, or tritium breeding compartment of the blanket the nuclear heating is due mainly to neutrons. The spikes in the heating curves are due to gamma-ray heating in the stainless steel structural members within the blanket. In the outer portion of the blanket, gamma rays produced from inelastic neutron reactions and thermal neutron capture reactions with stainless steel nuclei contribute the largest fraction to the nuclear heating. 


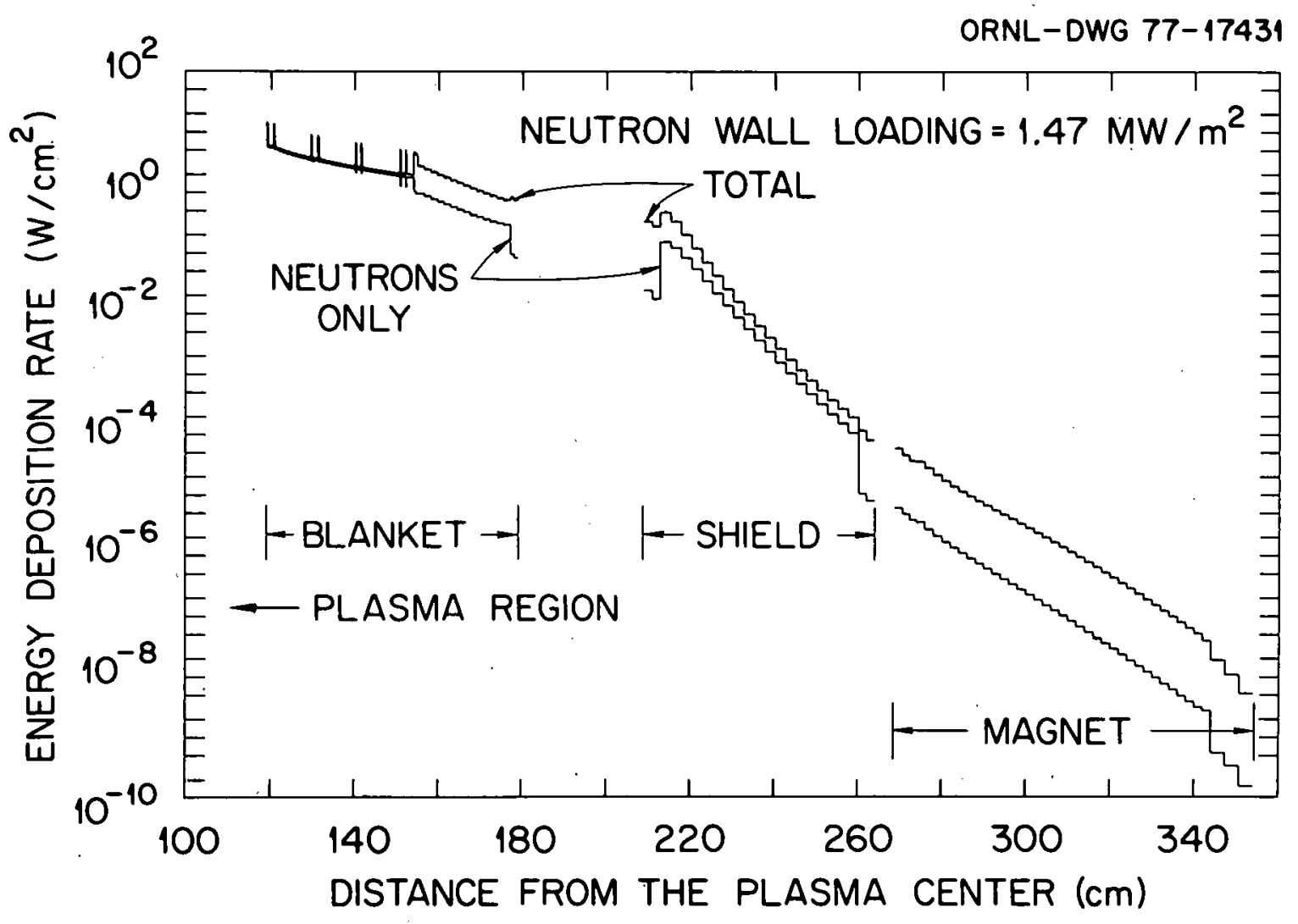

Fig. 1. The Energy Deposition Rates as a Function of Distance from the Plasma Centerline. 
The peak heating rate in the shield assembly is $0.34 \mathrm{w} / \mathrm{cm}^{3}$. The energy deposition rate drops off almost four orders of magnitude through the shield and at the front surface of the magnet assembly the peak heating rate is down to $5.8 \times 10^{-5} \mathrm{w} / \mathrm{cm}^{3}$. The heating rate in the magnet assembly is dominated by secondary gamma rays produced by thermal neutron capture reactions in the copper and stainless steel in the magnet.

The volume-integrated neutron, gamma ray, and total heating rates in the various reactor components are given in Table 4. Approximately $96 \%$ of the fusion neutron and secondary gamma-ray energy is recovered in the blanket assembly. The shield assembly absorbs $\sim 4 \%$ of the fusion energy and the remainder $(\ll 1 \%)$ is absorbed in the magnet coil assembly. The total energy recovered in the reactor is $18.7 \mathrm{MeV} /$ neutron resulting in a net gain in the power output of the system. This advantage results mainly from the exothermic $n+6 \mathrm{Li}$ reactions $(Q=+4.78 \mathrm{MeV})$ that occur in the breeding compartment in the blanket assembly.

An important consideration in the design of the EBTR was to minimize the nuclear heating rate in the cryogenic magnet coil assembly. The state-of-the-art in cryogenic magnet design for fusion reactor application, combined with cost and magnetic field requirements, limit the inner bore dimensions of magnet coils. Also, the dimensions and composition of the blanket assembly were established by mechanical design and heat recovery considerations. The added constraint for a 30-cm-thick maintenance channel between the blanket shield resulted in an allowed shield thickness of $55 \mathrm{~cm}$. Calculations were carried out to compare the energy deposition rate in the magnet assembly as a function of the shield composition. 
Table 4. Volume-Integrated Neutron and Gamma-Ray Contributions to the Heating Rate in the EBTR Reference Design

\begin{tabular}{|c|c|c|c|c|}
\hline \multirow[b]{2}{*}{ Reactor Component } & \multicolumn{4}{|c|}{ (Neutron Wall Loading $=1.47 \mathrm{MW} / \mathrm{m}^{2}$ ) } \\
\hline & $\begin{array}{l}\text { Neutron } \\
\text { Heating Rate } \\
(w)\end{array}$ & $\begin{array}{l}\text { Gamma-Ray } \\
\text { Heating Rate } \\
\text { (w) }\end{array}$ & $\begin{array}{l}\text { Total } \\
\text { Heating Rate } \\
\text { (w) }\end{array}$ & $\begin{array}{l}\text { Fractional } \\
\text { Heating Rate } \\
\qquad(\%)\end{array}$ \\
\hline \multicolumn{5}{|l|}{ Blanket Assembly } \\
\hline First Wall & $4.60 \times 10^{2}$ & $3.55 \times 10^{2}$ & $8.15 \times 10^{2}$ & 0.55 \\
\hline Breeding Section & $8.75 \times 10^{4}$ & $1.75 \times 10^{4}$ & $1.05 \times 10^{5}$ & 70.7 \\
\hline Gamma-Ray Shield & $1.42 \times 10^{4}$ & $2.00 \times 10^{4}$ & $3.42 \times 10^{4}$ & 24.6 \\
\hline$\underline{\text { Shield }}$ & $1.85 \times 10^{3}$ & $4.14 \times 10^{3}$ & $5.99 \times 10^{3}$ & 4.12 \\
\hline \multicolumn{5}{|l|}{ Magnet Coil } \\
\hline Bobbin & $4.19 \times 10^{-2}$ & $3.52 \times 10^{-1}$ & $3.94 \times 10^{-1}$ & $2.7 \times 10^{-4}$ \\
\hline Coil Windings & $6.10 \times 10^{-2}$ & $5.89 \times 10^{-1}$ & $6.50 \times 10^{-1}$ & $4.4 \times 10^{-4}$ \\
\hline SS-316 Structure & $7.44 \times 10^{-6}$ & $2.43 \times 10^{-4}$ & $2.50 \times 10^{-4}$ & $2.0 \times 10^{-7}$ \\
\hline TOTAL HEATING RATE & $1.05 \times 10^{5}$ & $4.20 \times 10^{4}$ & $1.47 \times 10^{5}$ & 100.00 \\
\hline MeV per Neutron & 13.4 & 5.3 & 18.7 & \\
\hline
\end{tabular}

The volume-integrated nuclear heating rate in the magnet assembly as a function of the composition of the shield is summarized in Table 5 . In all cases, the shield is composed of stainless steel and water, or borated water, combined in various mixtures. These materials were selected because of their shielding properties with water serving both as shielding and as a coolant for removing heat from the shield assembly. In shields 1-4, stainless steel and water are homogenized in different proportions with different boron concentrations in the water. Shields 5-7 are laminated designs with each lamination containing stainless steel, and water, or both, in various proportions. 
Table 5. Volume-Integrated Nuclear Heating Rate in the Magnet Assembly as a Function of the Shield Composition

\section{Neutron Wall Loading $=1.47 \mathrm{MW} / \mathrm{m}^{2}$}

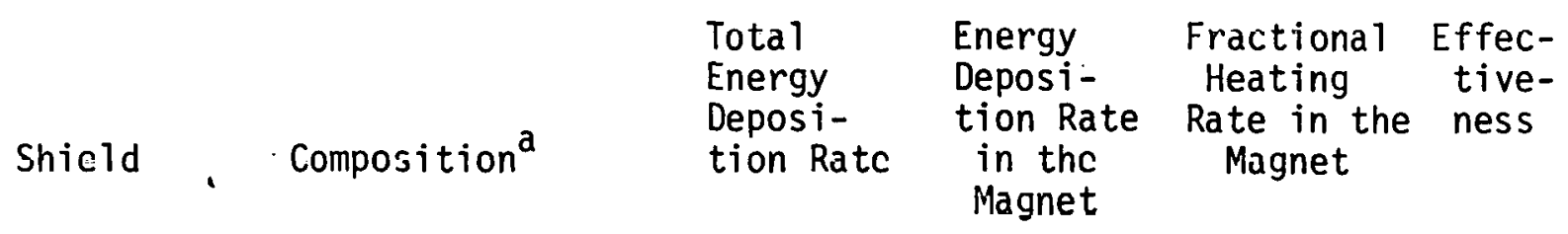

(w) (w)

(\%)

\begin{tabular}{llllllr}
\hline 1 & $65 \%$ SS-316+35\% & $\mathrm{H}_{2} 0 \cdot \mathrm{B} ; 6 \% \mathrm{~B}$ & $1.47 \times 10^{5}$ & 1.40 & $7.10 \times 10^{-4}$ & $(1)$ \\
2 & $65 \%$ SS-316+35\% & $\mathrm{H}_{2} \mathrm{O} \cdot \mathrm{B} ; 1 \% \mathrm{~B}$ & $1.52 \times 10^{5}$ & 1.56 & $1.03 \times 10^{-3}$ & $(.69)$ \\
3 & $50 \%$ SS-316+50\% & $\mathrm{H}_{2} \mathrm{O}$ & $1.52 \times 10^{5}$ & 3.98 & $2.62 \times 10^{-3}$ & $(0.27)$ \\
4 & $50 \% \mathrm{SS}^{2} 316+50 \%$ & $\mathrm{H}_{2} \mathrm{O} \cdot \mathrm{B} ; 1 \% \mathrm{~B}$ & $1.54 \times 10^{5}$ & 51.0 & $3.31 \times 10^{-2}$ & $(.02)$ \\
5 & Laminated $^{\mathrm{a}}$ & & $1.49 \times 10^{5}$ & 4.59 & $3.09 \times 10^{-3}$ & $(.23)$ \\
6 & Laminated $^{\mathrm{b}}$ & $1.49 \times 10^{5}$ & 23.9 & $1.61 \times 10^{-2}$ & $(.04)$ \\
7 & Laminated $^{\mathrm{C}}$ & $1.43 \times 10^{5}$ & 5.19 & $3.64 \times 10^{-3}$ & $(.20)$ \\
\hline
\end{tabular}

${ }^{\mathrm{a}}$ Composition used in the $0.4738-\mathrm{m}$-thick bulk shielding compartment. See Table 2.

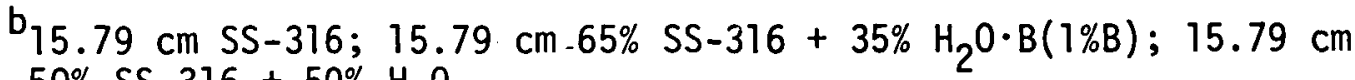
$50 \% \mathrm{SS}-316+50 \% \mathrm{H}_{2} 0$.

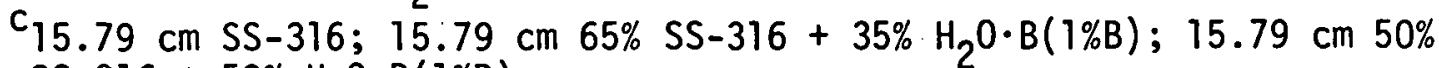
$\mathrm{SS}-316+50 \% \mathrm{H}_{2} \mathrm{O} \cdot \mathrm{B}(1 \% \mathrm{~B})$

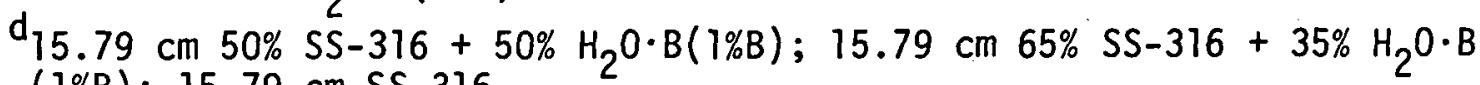
$(1 \% \mathrm{~B}) ; 15.79 \mathrm{~cm} \mathrm{SS}-316$.

Shield composition 1 ( $65 \%$ SS-316; 35\% $\mathrm{H}_{2} \mathrm{O} \cdot \mathrm{B}$ with $6 \%$ boron concentration) is the most effective combination of the materials that were considered.for reducing the energy deposition rate in the magnet assembly. The effectiveness of the other material combinations are compared relative to shield composition 1 in the last column in Table 5.

The spatial distributions of the tritium breeding in the EBTR blanket assembly are shown in Fig. 2. The curves labelled $6 \mathrm{Li}$ show the tritium 


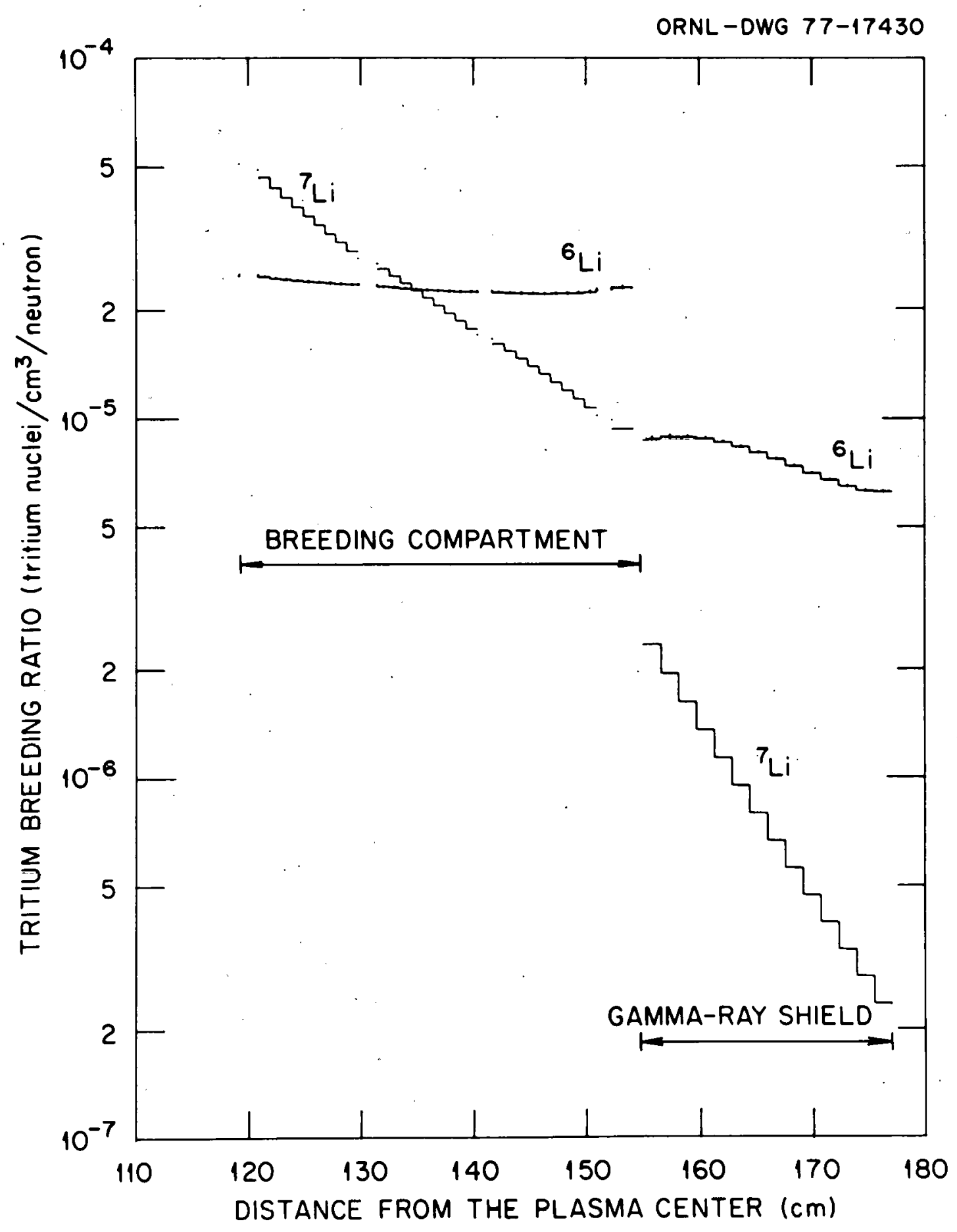

Fig. 2. The Spatial Distributions of the Tritium Breeding Ratio from Neut.ron Rear.tinns with the ${ }^{6} \mathrm{~L} i$ and ${ }^{7} \mathrm{Li}$ Isutupes. 
production from the ${ }^{6} \mathrm{Li}(n, \alpha) T$ reaction and the curves labelled ${ }^{7} \mathrm{Li}$ show the tritium production from the ${ }^{7} L i\left(n, n^{\prime} \alpha\right) T$ reaction. The sharp transition in the curves at $156 \mathrm{~cm}$ from the plasma centerline occurs because the volume fraction of lithium in the blanket gamma-ray shield is smaller (35\%) than in the breeding compartment. The tritium production from neutron reactions with ${ }^{7} \mathrm{Li}$ is due to fast neutrons ( $\mathrm{E}>2.5 \mathrm{MeV}$ ) throughout the blanket. Tritium production from neutron reactions with ${ }^{6} \mathrm{Li}$ occurs with neutrons that have been substantially moderated in the blanket. The volume-integrated tritium breeding ratios in the various lithium-laden zones in the blanket from neutron reactions with ${ }^{6} \mathrm{Li}$ and ${ }^{7} \mathrm{Li}$ are summarized in Table 6 . The total tritium breeding ratio is 1.29 tritium nuclei per incident neutron. Neutron reactions with ${ }^{6} \mathrm{Li}$ account for $\sim 56 \%$ of the total tritium production.

Table 6. Tritium Breeding Ratio in the EBTR Reference Design

Tritium Nuclei/Incident Neutron

Zone Thickness

(cm)

\begin{tabular}{rrrrr}
\hline 5 & 0.05 & $9.41 \times 10^{-4}$ & $1.93 \times 10^{-3}$ & $2.87 \times 10^{-3}$ \\
9 & 0.05 & $9.50 \times 10^{-4}$ & $1.87 \times 10^{-3}$ & $2.82 \times 10^{-3}$ \\
11 & 8.75 & $1.65 \times 10^{-1}$ & $2.55 \times 10^{-1}$ & $4.20 \times 10^{-1}$ \\
13 & 0.05 & $9.57 \times 10^{-4}$ & $1.14 \times 10^{-3}$ & $2.10 \times 10^{-3}$ \\
17 & 0.05 & $9.65 \times 10^{-4}$ & $1.11 \times 10^{-3}$ & $2.08 \times 10^{-3}$ \\
19 & 8.75 & $1.70 \times 10^{-1}$ & $1.62 \times 10^{-1}$ & $3.32 \times 10^{-1}$ \\
21 & 0.04 & $7.91 \times 10^{-4}$ & $6.00 \times 10^{-4}$ & $1.39 \times 10^{-3}$ \\
25 & 0.04 & $7.99 \times 10^{-4}$ & $5.91 \times 10^{-4}$ & $1.39 \times 10^{-3}$ \\
27 & 9.13 & $1.87 \times 10^{-1}$ & $1.11 \times 10^{-1}$ & $2.98 \times 10^{-1}$ \\
29 & 0.04 & $8.59 \times 10^{-4}$ & $3.84 \times 10^{-4}$ & $1.24 \times 10^{-3}$ \\
33 & 0.04 & $8.73 \times 10^{-4}$ & $3.77 \times 10^{-4}$ & $1.25 \times 10^{-3}$ \\
35 & 1.76 & $3.91 \times 10^{-2}$ & $1.57 \times 10^{-2}$ & $5.48 \times 10^{-2}$ \\
37 & $7.72^{\mathrm{a}}$ & $1.50 \times 10^{-1}$ & $1.77 \times 10^{-2}$ & $1.68 \times 10^{-1}$ \\
TOTAL & 36.47 & $7.18 \times 10^{-1}$ & $5.69 \times 10^{-1}$ & $1.29 \times 10^{0}$
\end{tabular}

$\mathrm{a}_{\text {Effective }}$ ithium thickness in the blanket gamma-ray shield. 
The radiation damage in the stainless steel structural components at various locations in the EBTR are given in Table 7 . The damage is given in terms of the atomic displacement rate (dpa/yr) and in terms of the hydrogen and helium gas production rates (appm/year). The hydrogen gas production includes the contributions from the $(n, p)$ and $\left(n, n^{\prime}\right) p$ reactions and the helium gas production includes the $(n, \alpha)$ and $\left(n, n^{\prime}\right) \alpha$ reactions. The data are normalized to a neutron wall loading of $1.47 \mathrm{MW} / \mathrm{m}^{2}$.

Table 7. Spatial Dependences of the Atomic Displacement and Gas Production Rates in the SS-316 Structure at Various Locations in the EBTR Reference Design

Neutron Wall Loading $=1.47 \mathrm{MW} / \mathrm{m}^{2}$

Location

Atomic Displacement Ratea

(DPA/Year)
Hydrogen

Gas Production Rate

$(\text { APPM/Year })^{\mathrm{b}}$
Helium Gas Production Rate

(APPM/Year)

First structural wall

20.9

913.

276.

Center of blanket

(Zone 28)

\subsection{2}

127.

34.7

Rear of blanket

$7.70 \times 10^{-1}$

7.43

1.91

Front of shield

$2.16 \times 10^{-1}$

1.45

$3.62 \times 10^{-1}$

Rear of shield

$4.92 \times 10^{-5}$

$1.11 \times 10^{-3}$

$2.74 \times 10^{-4}$

Front of magnet coil

$3.51 \times 10^{-5}$

$5.13 \times 10^{-4}$

$1.26 \times 10^{-4}$

Rear of magnet coil

$6.26 \times 10^{-9}$

$6.76 \times 10^{-10}$

$1.67 \times 10^{-10}$

${ }^{a}$ Based on an effective displacement energy of $40 \mathrm{eV}$.

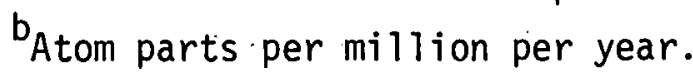

The atomic displacement rate in the stainless-steel structure adjacent to the plasma region is $20: 9 \mathrm{dpa} / \mathrm{yr}$, or $14.2 \mathrm{dpa} / \mathrm{yr} /\left(\mathrm{MW} / \mathrm{m}^{2}\right)$. This value is 
larger than that reported for the first wall in the earlier version of the EBTR 1 of $10.7 \mathrm{dpa} / \mathrm{yr} /\left(\mathrm{MW} / \mathrm{m}^{2}\right)$. In the design in Ref. 1, the first wall was shadowed from the plasma by sodium-hydroxide-filled, stainlesssteel cooling tubes which, in the calculational model, modified the neutron spectrum over the entire'first wall. The atomic displacement rate in the stainless-steel cooling tubes was, $13.5 \mathrm{dpa} / \mathrm{yr} /\left(\mathrm{MW} / \mathrm{m}^{2}\right)$ which is consistent with the value in Table 7. The atomic displacement rate decreases rapidly with increasing distance through the reactor assembly. The damage rate is a factor of 27 smaller in the structure at the rear of the blanket assembly and greater than five orders of magnitude smaller at the rear of the shield assembly.

The hydrogen and helium gas production rates in the stainless steel structure adjacent to the plasma are $913 \mathrm{appm} / \mathrm{yr}$ and $276 \mathrm{appm} / \mathrm{yr}$, respectively. These values are higher than those previously reported for the EBTR for the same reasons as cited above. The hydrogen gas production rate decreases by a factor of $\sim 122$ through the blanket and by nearly six orders of magnitude at the rear of the shield. The helium gas production rate at these same locations is reduced by a factor of 144 and nearly six orders of magnitude, respectively.

The spatial distributions of the atomic displacement rate and gas production rates in the stainless steel structure may be found in Appendix A.

The spatial distributions of the atomic displacement and gas production rates in the copper and niobium in the magnet windings are shown in Figs. 3 and 4 , respectively. The effective displacement threshold used in the calculations are $30 \mathrm{eV}$ for copper and $60 \mathrm{eV}$ for niobium. The 


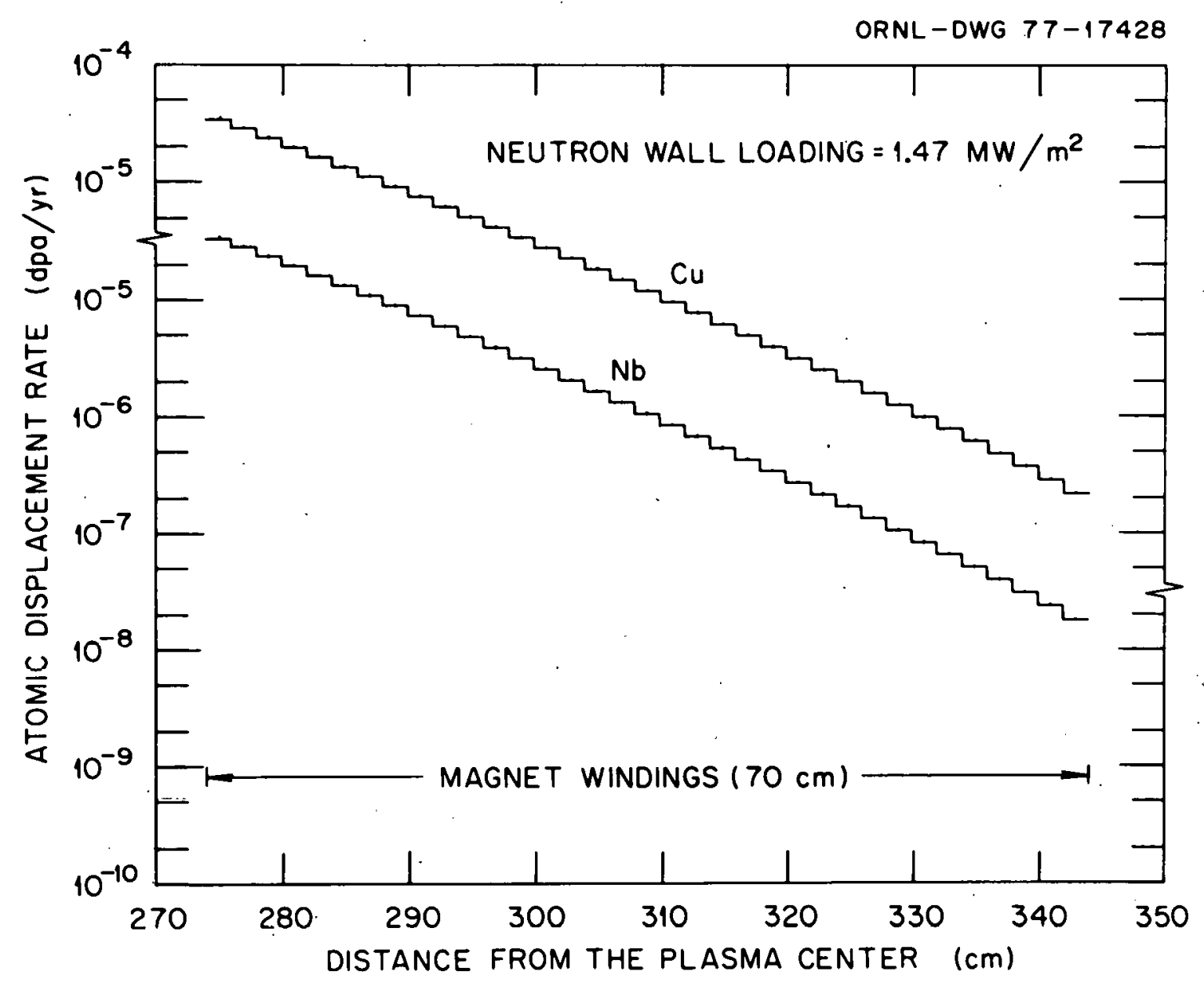

Fig. 3. The Atomic Displacement Rate as a Function of Depth in the Magnet Coil Assembly. 


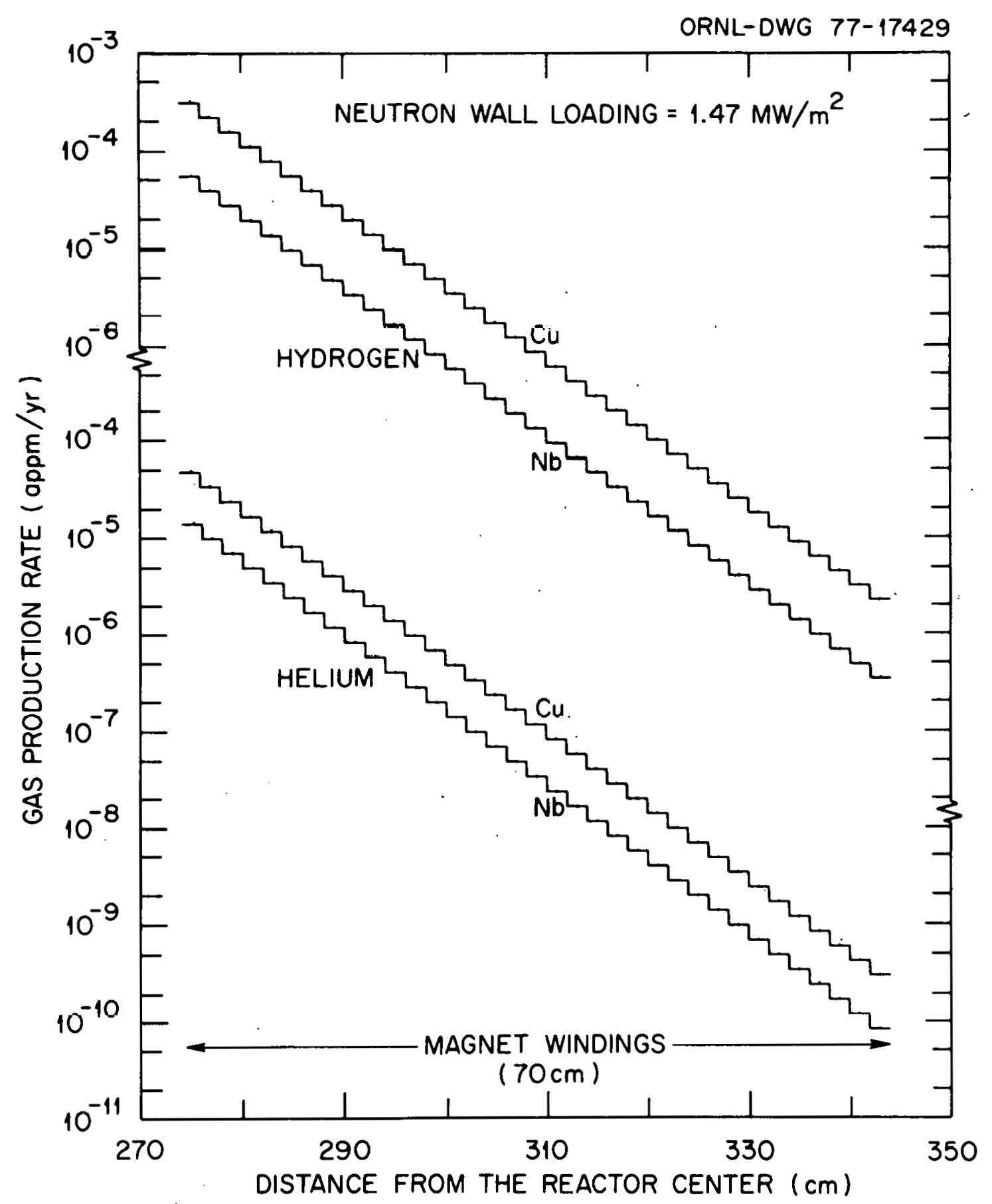

Fig. 4. The Hydrogen and Helium Gas Production Rates as a Function of Depth in the Magnet Coil Assembly. 
atomic displacement curves in Fig. 3 have been shifted by a factor of ten in the ordinate to show the results more clearly. Except at large depths in the magnet windings, the values for the atomic displacement rate are very nearly the same. Note also that the ordinate in Fig. 4 has been broken in order to display the hydrogen and helium gas production rates in the same graph. 


\section{THIS PAGE \\ WAS INTENTIONALLY \\ LEFT BLANK}




\section{Appendix A}

Supplementary data that were calculated to estimate the nuclear performance of the EBTR reference design are included in this appendix.

Fig. A.l shows the spatial dependence of the atomic displacement rate as a function of location in the reactor. The spatial distributions of the gas production rates are shown in Fig. A.2. The upper curves show the spatial distribution of the hydrogen gas production rate and the lower curves the corresponding distribution for the helium production rate. In both figures, the data are normalized to a neutron wall loading of $1.47 \mathrm{MW} / \mathrm{m}^{2}$.

The spatial dependence of the energy integrated omnidirectional neutron flux distributions are shown in Fig. A3. These data were obtained by evaluating the expression

$$
\phi(r ; \not E)=\int_{E}^{E_{\max }} \phi\left(r, E^{\prime}\right) \mathrm{dE}^{\prime} ; E_{\max }=14 \mathrm{MeV}
$$

at each spatial location in the reactor for values of $E$ of $14,10,1,0.1$, and $10^{-10} \mathrm{MeV}$. The fraction of low energy neutrons at each spatial location increases with increasing depth in the reactor. The ratio $\phi(E>$ Thermal $) / \phi(E=14 \mathrm{MeV})$ is $\sim 20$ at the rear of the blanket assembly and increases to $\sim 2 \times 10^{3}$ at the center of the magnet assembly. The $14-\mathrm{MeV}$ neutron flux is reduced by factors of $6 \times 10^{2}, 4 \times 10^{6}$, and $7 \times 10^{12}$ in passage through the blanket, shield, and magnet assemblies, respectively. The flux integrated over all neutron energies, $\phi(E>$ Therma 1$)$, is down by factors of $7,10^{5}$, and $6 \times 10^{8}$ at these same locations. 
The spatial dependence of the energy integrated ominidirectional gamma-ray flux, $\phi(a) 1 E)$, is shown in Fig. A4. 


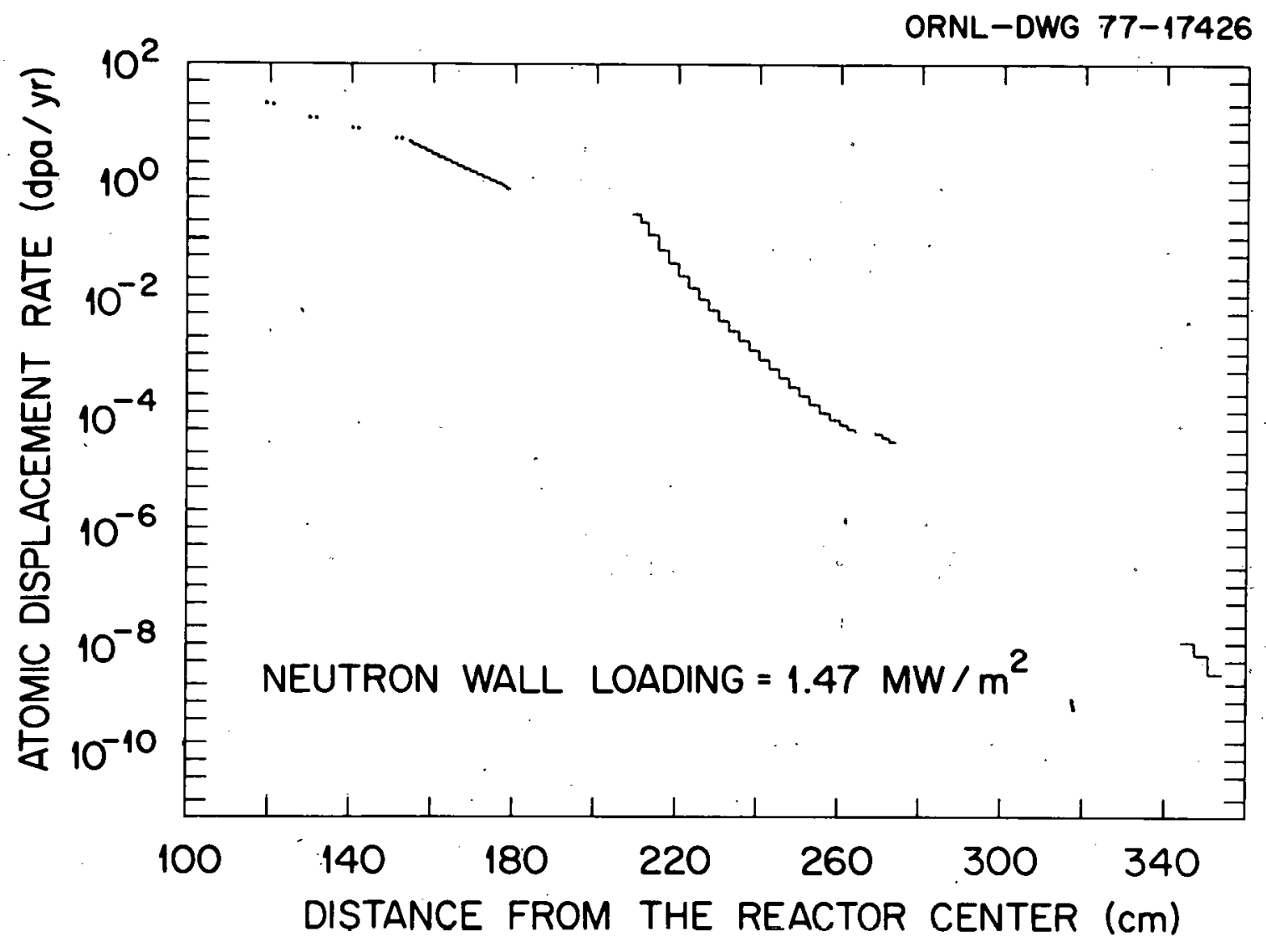

Fig. A1. The Atomic Displacement Rate in SS-316 as a Function of Distance from the Plasira Ceriterline. 


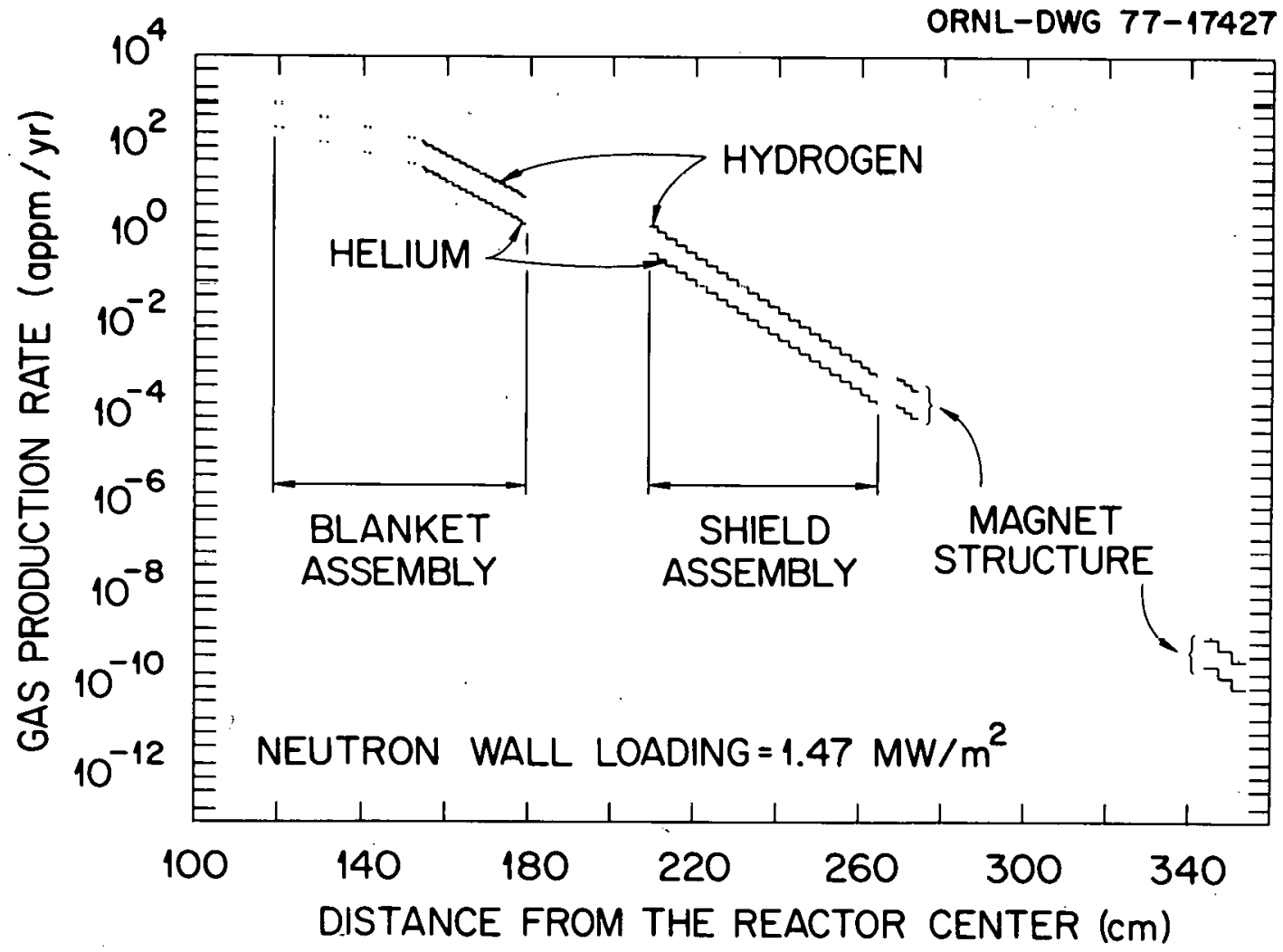

Fig. A2. The Hydrogen and Helium Gas Production Rates in SS-316 as a Function of Distance from the Plasma Centerline. 


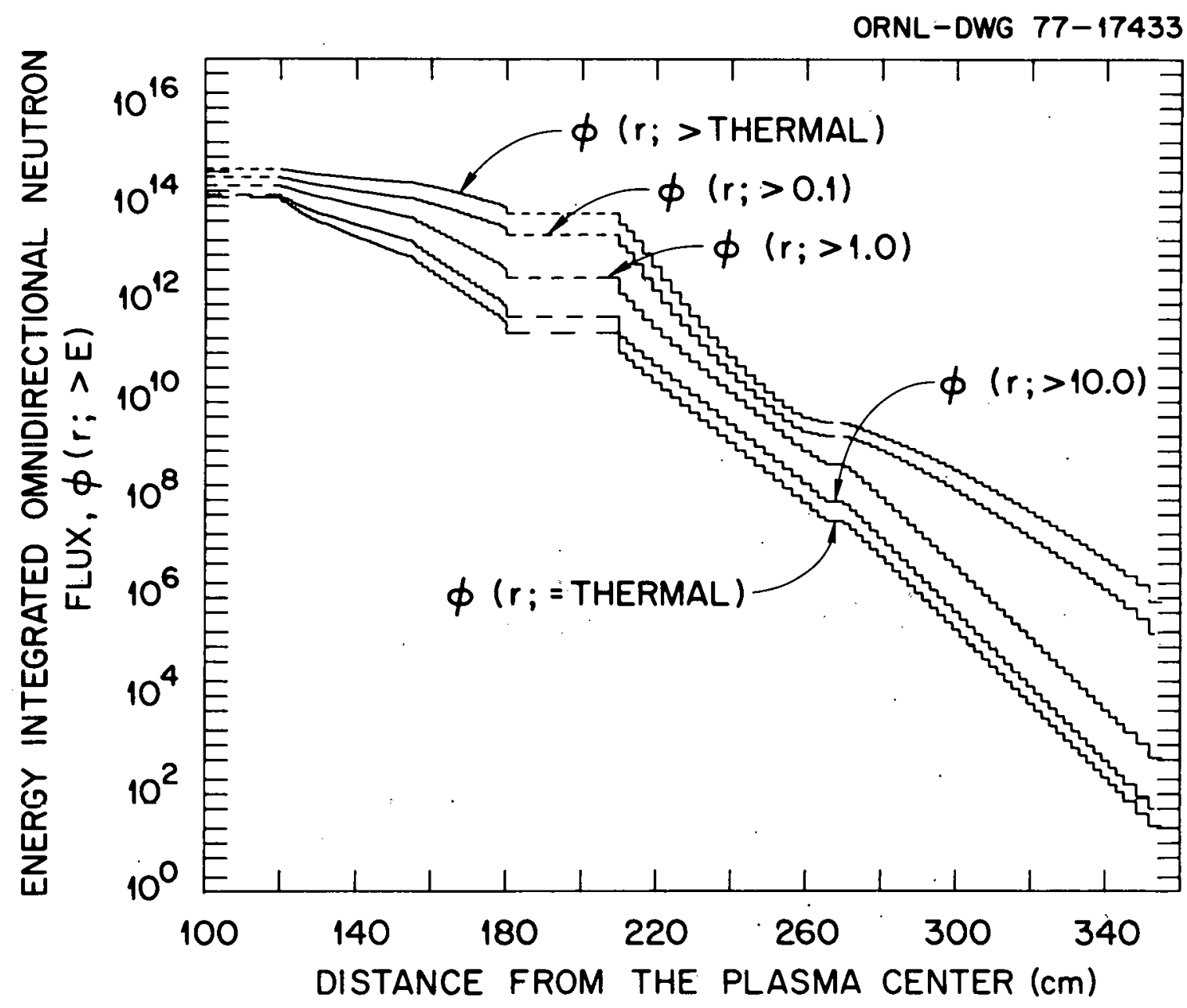

Fig. A3. The Spatial Dependence of the Energy Integrated Omnidirectional Neutron Flux, $\phi(>E)$, Distributions. 


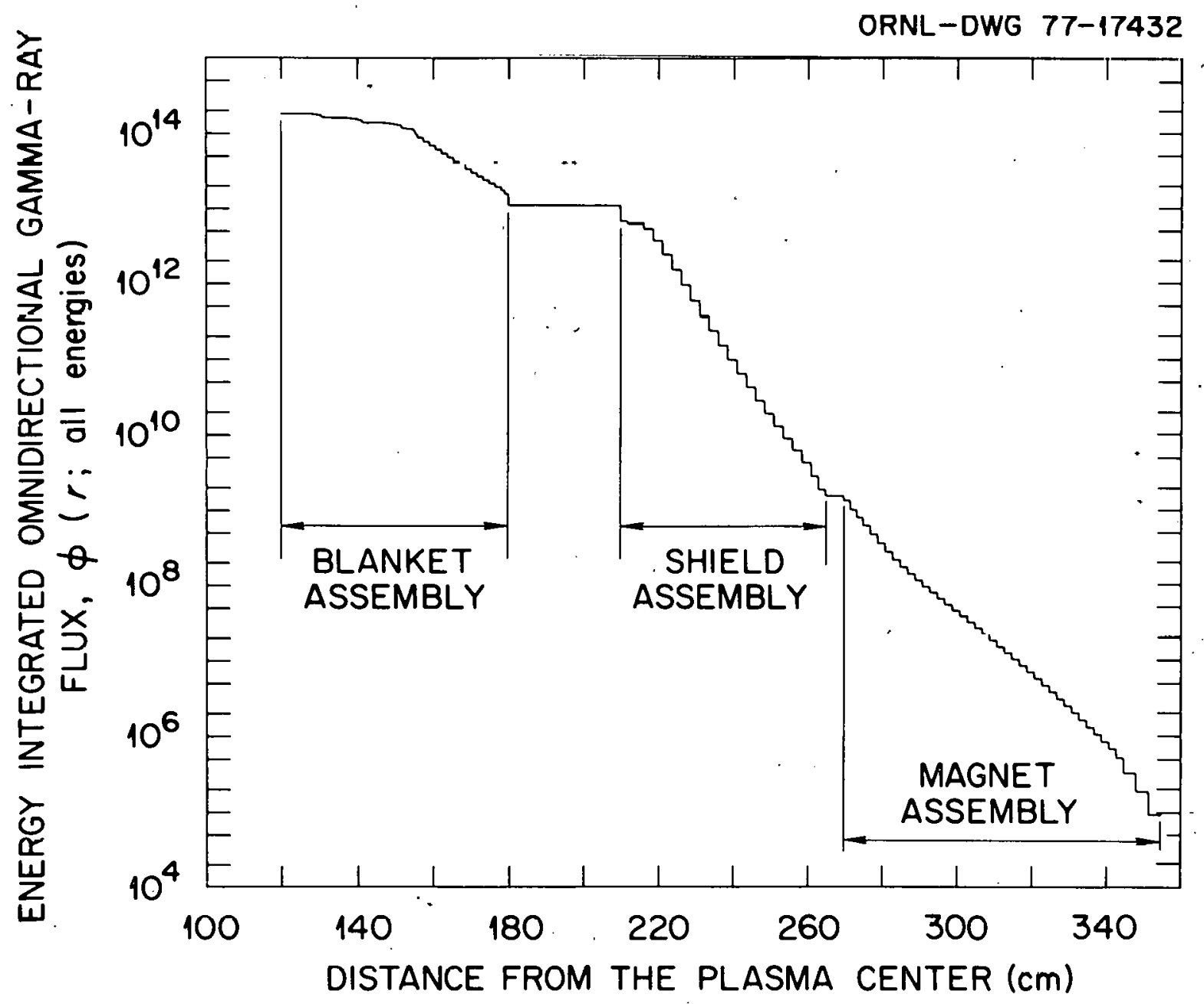

Fig. A4. The Spatial Dependence of the Energy Integrated Omnidirectional Gamma-Ray Flux $\phi$ (a11 energy). 


\section{REFERENCES}

1. D: G. McAlees et al., "The ELMO Bumpy Torus Reactor (EBTR) Reference Design", ORNL/TM-5669, Oak Ridge National Laboratory (1976).

2. N. A. Uckan et al., "The ELMO Bumpy Torus Reactor", ORNL/TM-6084, Oak Ridge National Laboratory. (In press)

3. N. A. Uckan and C. L. Hedrick, "Plasma Simulation and Modeling for the ELMO Bumpy Torus", ORNL/TM-6019, Oak Ridge National Laboratory. (In press)

4. M. Roberts and E. S. Bettis, "Oak Ridge Tokamak Experimental Power Reactor Study Reference Design", ORNL/TM-5042, Oak Ridge National Laboratory (1975).

5. R. T. Santoro et.al., "Neutronic Scoping Studies for the Tokamak Experimental Power Reactor", ORNL/TM-5035, Oak Ridge National Laboratory (1976).

6. M. A. Abdou, Nucl. Technology 29, 7 (1976).

7. W. W. Engle, Jr., "A User's Manual for ANISN, a One-Dimensional Discrete Ordinates Code with Anisotropic Scattering", Report K-1693, Computing Technology Center, Union Carbide Corporation (1967).

8. W. E. Ford, III, R. T. Santoro, R. W. Roussin, and D. M. Plaster, "Modification Number One to the Coupled 100n-2ly Cross Section Library for EPR Calculations", ORNL/TM-5249, Oak Ridge National Laboratory (1976).

9. M. A. Abdou, C. W. Maynard, and R. G. Wright, "MACK - A Computer Program to Calculate Neutron Energy Release Parameters (Fluence-toKerma Factors) and Multigroups Neutron Reaction Cross Sections 


\section{References (Cont'd)}

from Nuclear Data in ENDF Format", ORNL/TM-3994, Oak Ridge National Laboratory (1973).

10. M. A. Abdou and R. W. Rouss in, "MACKLIB-100-Group Neutron Fluenceto-Kerma Factors and Reaction Cross Section Generated by the MACK Computer Program from Data in ENDF Format", ORNL/TM-3995, Oak Ridge National Laboratory (1974).

11. N. M. Greene et al., "AMPX: A Modular Code System for Generating Coupled Multigroup Neutron-Gamma Libraries from ENDF/B", ORNL/TM-3706, Oak Ridge National Laboratory (1976).

12. T. A. Gabrie1, J. D. Amburgey, and N. M. Greene, "Radiation-Damage Calculations: Primary Recoil Spectra, Displacement Rates, and GasProduction Rates", ORNL/TM-5160, Oak Ridge National Laboratory (1976). 
ORNL/TM-6085

Internal Distribution

$\begin{aligned} & \text { 1. } \text { L. S. Abbott } \\ & \text { 2. } \text { F. S. Alsmiller } \\ & \text { 3. } \text { R. G. Alsmiller, Jr. } \\ & \text { 4-5. J. M. Barnes } \\ & \text { 6. J. Barish } \\ & \text { 7. } \text { E. S. Bettis } \\ & \text { 8. R. A. Dandl } \\ & \text { 9. T. A. Gabriel } \\ & \text { 10. H. Goldstein (consultant) } \\ & \text { 11. F. Hammerling } \\ & \text { 12. C. L. Hedrick } \\ & \text { 13. T. J. Huxford } \\ & \text { 14. R. A. Lillie } \\ & \text { 15. F. C. Maienschein } \\ & \text { 16. O. B. Morgan, Jr. } \\ & \text { 17. E. M. Oblow } \\ & \text { 18. M. Roberts } \\ & \text { 19. M. W. Rosenthal } \\ & \text { 20. R. W. Roussin } \\ & \text { 21. RSIC Ro Santoro } \\ & \text { 22-40. R. T. Santoro }\end{aligned}$

\author{
41. J. L. Scott \\ 42. D. Steiner \\ 43. M. L. Tobias \\ 44-45. N. A. Uckan \\ 46. J. S. Watson \\ 47. C. R. Weisbin \\ 48. H. T. Yeh \\ 49. A. Zucker \\ 50. P. F. Fox (consultant) \\ 51. W. W. Havens, Jr. (consul tant) \\ 52. A. F. Henry (consultant) \\ 53. R. E. Uhrig (consultant) \\ 54-55. Central Research Library \\ 56. ORNL Y-12 Technical Library \\ Document Reference Section \\ 57. Laboratory Records Department \\ 58. Laboratory Records ORNL RC \\ 59. ORNL Patent Office
}

External Distribution.

60. J. F. Clarke, Division of Magnetic Fusion Energy, Department of Energy, Washington, DC 20545

61. F. E. Coffman, Division of Magnetic Fusion Energy, Department of Energy, Washington, DC 20545

62. N. A. Davies, Division of Magnetic Fusion Energy, Department of Energy, Washington, DC 20545

63. S. 0. Dean, Division of Magnetic Fusion Energy, Department of Erieryy, Washington, DC 20545

64. W. Ellis, Division of Magnetic Fusion Energy, Department of Energy, Washington, DC 20545

65. C. R. Head, Division of Magnetic Fusion Energy, Department of Energy, Washington, DC 20545

66-67. R. Hensler, Ebasco Services, Inc., Two Rector St., NY, NY 10006

68. E. E. Kintner, Division of Magnetic Fusion Energy, Department of Energy, Washington, DC 20545

69. Dr. D. G. McAlees, Exxon Nuclear Corp., Research \& Technology Center, Laser Enrichment Ũept., 2955 George Washington Way, Richland, WA 99352

70. J. 0. Neff, Division of Magnetic Fusion Energy, Department of Energy, Washington, DC 20545

71. R. E. Price, Division of Magnetic Fusion Energy, Department of Energy, Washington, DC 20545

72-98. Technical Information Center (TIC)

99. Department of Energy, Research \& Technical Support Division, P.0. Box E, Oak Ridge, TN 37830: Director

100-145. Given NPD-CTR External Distribution 